\title{
Opportunistic wetland formation, characterization, and quantification on landforms reclaimed to upland ecosites in the Athabasca Oil Sands Region
}

\author{
Virgil C. Hawkes (D) Michael T. Miller • Julio Novoa $・$ Ebere Ibeke • \\ Joshua P. Martin
}

Received: 17 December 2019/Accepted: 13 October 2020/Published online: 20 October 2020

(C) The Author(s) 2020

\begin{abstract}
Surface mine operators in the Athabasca Oil Sands Region (AOSR) of northeastern Alberta are required by regulation to mitigate habitat impacts resulting from their operations, including impacts to wetlands. To date, most land reclamation efforts have focused on recreating upland forestlands that resemble the surrounding natural (dry) boreal forest. However, the surficial conditions on these reclaimed upland sites can also promote spontaneous wetland development. At Suncor's Base Plant mine, opportunistic wetlands occurring on reclamation sites have not been formally included in the current inventory of reclaimed wetland areas and remain largely unquantified. We characterized and delineated an estimated 210 ha of opportunistic wetlands (consisting of shallow open water, marshes, and swamps) using aerial photo interpretation and remote sensing analysis in combination with follow-up field verifications. The remote-based (desktop) delineations consistently underestimated actual wetland extents, due mainly to underestimations in the extent of non-inundated vegetation zones (e.g., wet meadow) as well as shrubby swamp. After field corrections, opportunistic wetland habitat was estimated to constitute $\sim 17 \%$ of the total study area
\end{abstract}

V. C. Hawkes $(\bowtie) \cdot$ M. T. Miller · J. Novoa

LGL Limited environmental research associates, Sidney,

BC, Canada

e-mail: vhawkes@lgl.com

E. Ibeke · J. P. Martin

Suncor Energy Inc., Calgary, AB, Canada
(1209 ha), representing more than a fourfold increase in aerial wetland extent associated with reclaimed landforms over that delineated prior to this study. The interspersion of opportunistic wetlands with upland reclaimed landforms, although unintended, more closely reflects the pre-disturbance landscape, which was characterized by a matrix of forestlands, peatlands, and mineral wetlands (in contrast to the more peatland-dominated lowlands). At Suncor, wetland vegetation composition varied significantly across the study area and was influenced by topographic variation (e.g., in elevation and \% slope) in combination with the reclamation substrates (soils) that were placed prior to seeding/planting. Thus, the inclusion of opportunistic wetland delineation in reclamation tracking and closure planning merits consideration as does the opportunity to manipulate current reclamation practices to promote the establishment and persistence of wetlands on reclaimed landforms.

Keywords Opportunistic wetland $\cdot$ Reclaimed wetland · Alberta Oil sands - Reclamation - Remote sensing $\cdot$ Wetland classification

\section{Introduction}

The development of the Athabasca Oil Sands Region (AOSR) in northeastern Alberta brings large-scale and long-term anthropogenic disturbances that alter the 
mosaic of peatland-forest-mineral wetland complexes common in the Boreal Plains (Vitt and Chee 1989; Nwaishi et al. 2015a, b; Volik et al. 2020).

Between 1980 and 2017, the total land area impacted by surface mining and in-situ activities in the Lower Athabasca region of Alberta increased from 290 to 895 $\mathrm{km}^{2}$ (Government of Alberta 2017a). Within this forest-wetland mosaic, peatland wetlands (e.g., wooded and shrubby fens) are dominant upon the landscape, comprising up to $62 \%$ of the surface minable oil sands area, with mineral wetlands (e.g., shallow open water, marshes) constituting another $3 \%$ of the surface minable area (Raine et al. 2002). Consequently, oil sands development has disturbed the ecology and hydrology of many wetlands (Price et al. 2010; Daly et al. 2012; Rooney et al. 2012; Nwaishi et al. 2015a, b). Efforts to mitigate impacts to affected forest and wetland habitats are underway as mandated by government Environmental and Protection Act approvals. Specifically, reclamation regulations require oil sands operators to return disturbed lands to "equivalent land capability," a portion of which will be reclaimed to wetland ecosystems (Government of Alberta 2017b).

Land reclamation occurs on active oil sands leases (both open pit mines and in-situ operations) concurrent with bitumen extraction activities. Most reclamation in the AOSR has targeted the re-establishment of upland forest habitat that is similar to the surrounding, naturally occurring boreal forest (Rooney et al. 2012; Hawkes and Gerwing 2019), although work aimed at directly reclaiming/restoring wetlands has also occurred. To date, wetland reclamation efforts have resulted in the establishment of numerous shallow open water and marsh wetlands on several surface mining leases including the first two mines established in the region: Syncrude's Mildred Lake lease and Suncor's Base Plant (Daly et al. 2009; Daly et al. 2010; Daly 2011; Pollard et al. 2012; Daly et al. 2012; Mollard et al. 2015; Ketcheson et al. 2016; Vitt et al. 2016; Scarlett et al. 2017). As of 2018, for example, Suncor had permanently reclaimed over 2000 ha of disturbed land at its Base Plant, of which $\sim 48$ ha was constructed mineral wetland. Some attention has also been given to the reclamation of peatland ecosystems, particularly of fens, on these leases (Ketcheson et al. 2016; Wytrykush et al. 2012; Borkenhagen and Cooper 2015, 2019; Vitt et al. 2016). Compensation efforts for peatland (fen) loss have included constructed fen creation using peat material harvested from natural peatlands (Ketcheson et al. 2016; Borkenhagen and Cooper 2019).

Although unintended, soil reconstruction methods used to recreate upland forestlands can also produce wetland-forming conditions (Little-Devito et al. 2019). Upland reclamation generally involves application of peat-mineral mix or forest floor materials as a capping substrate on reclaimed land (Hemstock et al. 2010; MacKenzie and Quideau 2010; Pinno and Hawkes 2015). Slight irregularities in the placement of different capping materials (topsoil) over large (>100 ha) areas of uneven terrain results in a heterogeneous surface that produces patches of very wet to very dry microsites (Gingras-Hill et al. 2018). This heterogeneity creates opportunities for wetland plant communities to establish spontaneously, such as in depressions within peat-mineral mix applications (Trites and Bayley 2009; Gringas-Hill et al. 2018; Little-Devito et al. 2019) but potentially even on flat terrain where fine-textured soils with low water storage potential promote frequent surface saturation (Little-Devito et al. 2019). Under certain conditions, lateral groundwater flow from constructed watersheds can also maintain soil wetness sufficient for wetland development (Price et al. 2010; Ketcheson et al. 2017). Such wetlands can enhance the suitability of reclaimed upland landforms for wildlife, increase biodiversity, improve water quality, and facilitate recharge and water storage capacity (Alberta Environment 2000; Ketcheson et al. 2016; Calhoun et al. 2017).

The study of opportunistic wetland development in the AOSR is relatively recent. On Syncrude's Mildred Lake Lease, opportunistic wetlands on three reclaimed landforms were investigated to assess controls on their structure and formation and the role they play in the ecohydrology of constructed landforms in the AOSR (Little-Devito et al. 2019). At Suncor's Base Plant, opportunistic wetlands occurring on reclaimed sites have not been formally included in the current inventory of reclaimed wetland areas and remain largely unquantified. In particular, the total reclaimed area constituted by these features is not well-understood, nor is the contribution they could potentially be making to the reclamation or partial replacement of wetland habitat impacted by bitumen extraction activities in the AOSR.

Here we report the results of a two-phase study of opportunistic wetlands that formed on landforms 
reclaimed to an upland forest type on Suncor's Base Plant. The objectives were to: (1) use aerial photo interpretation and remote sensing analysis to identify, classify, and delineate opportunistic wetlands that have developed on upland reclamation areas; (2) conduct a similar desktop delineation of intentionally reclaimed (constructed) mineral wetlands; and (3) use follow-up ground surveys to verify the accuracy of the desktop delineations, determine seasonal permanence of wetlands, characterize wetland vegetation communities, and compare these communities across the different reclamation areas. Results from this work are considered in the context of reclamation requirements in the AOSR and the contribution that opportunistic wetlands forming on upland reclaimed landforms make in mitigating impacts to the landscape resulting from bitumen extraction. The role that opportunistic wetlands have in enhancing the suitability of upland reclaimed landforms for wildlife is also briefly discussed along with the potential problems they present for the structural integrity of permanently reclaimed upland landforms.

\section{Study area}

Suncor Base Plant is located approximately $40 \mathrm{~km}$ north of Fort McMurray, Alberta, Canada in the Central Mixedwood subregion of the Boreal Forest Natural Ecoregion of Alberta (Natural Regions Committee (NRC) 2006) and the Boreal Plains ecoregion of Canada. Of the 2000 ha of permanently reclaimed land at the mine, 1209 ha were remotely surveyed as part of this study. For purposes of wetland delineation, the study area was divided into 11 focal areas (Fig. 1). Each of these Areas of Interest (AOI) contained at least one of the following: (1) intentionally reclaimed (constructed) wetlands; (2) opportunistic wetlands (e.g., Fig. 2); or (3) topographic wetness information (derived with GIS; see "Methods"). Except for intentional wetlands, which were included in this study for comparative purposes, wetland reclamation was not an explicit consideration for the upland landforms and all wetlands sampled formed opportunistically on the landforms reclaimed to an upland forest type.

\section{Methods}

Phase 1: desktop delineation

Using available remote sensing data (satellite imagery, orthophoto mosaics, and digital elevation models), we identified potential opportunistic wetlands on landforms reclaimed to an upland forest type. All suspected wetland boundaries within the AOIs were manually mapped in a GIS (Fig. 1). Desktop delineation followed the Alberta Wetland Identification and Delineation Directive and the Guide for Assessing Permanence of Wetland Basins (Government of Alberta 2015; AEP 2014).

To predict wetland occurrence, we assessed eight orthophoto mosaics from 2007 to 2014 and 67 GeoEye-1 and WorldView-2 satellite images from 2008 to 2015 for the presence of wetlands or places where wetlands might occur. Available satellite images spanned all calendar months but did not include all possible month-year combinations (Novoa and Hawkes 2016). Most images were composed of three colour bands corresponding to the visible spectrum. A few had a fourth, infrared band, which is useful for detecting water content and for discriminating vegetation types. Three digital elevation models were used, including two from 2012 (terrain and surface models) and one from 2014 (terrain model). All elevation models were generated from LiDAR datasets and had $<1 \mathrm{~m}$ of spatial resolution.

Once areas with obvious water accumulation had been manually delineated in GIS, a topographic wetness index (TWI; Grabs et al. 2009) was calculated to improve the visual recognition of areas prone to moisture accumulation. We used TWI because the spectral signature of a wetland in the visible spectrum is not optimal for image classification algorithms (Amani et al. 2018) and produces low accuracy when using classical remote sensing methods. To calculate the TWI, we used a LiDAR digital terrain model (DTM) from October 2014 with an assumed (because metadata were not available) vertical accuracy of $\leq 30 \mathrm{~cm}$, which we compared to colour infrared aerial photography from September 2014. These were the most recent instances where spectral and elevation data were available for the same year and were thus considered the best available data sources for detecting potential wetlands. 


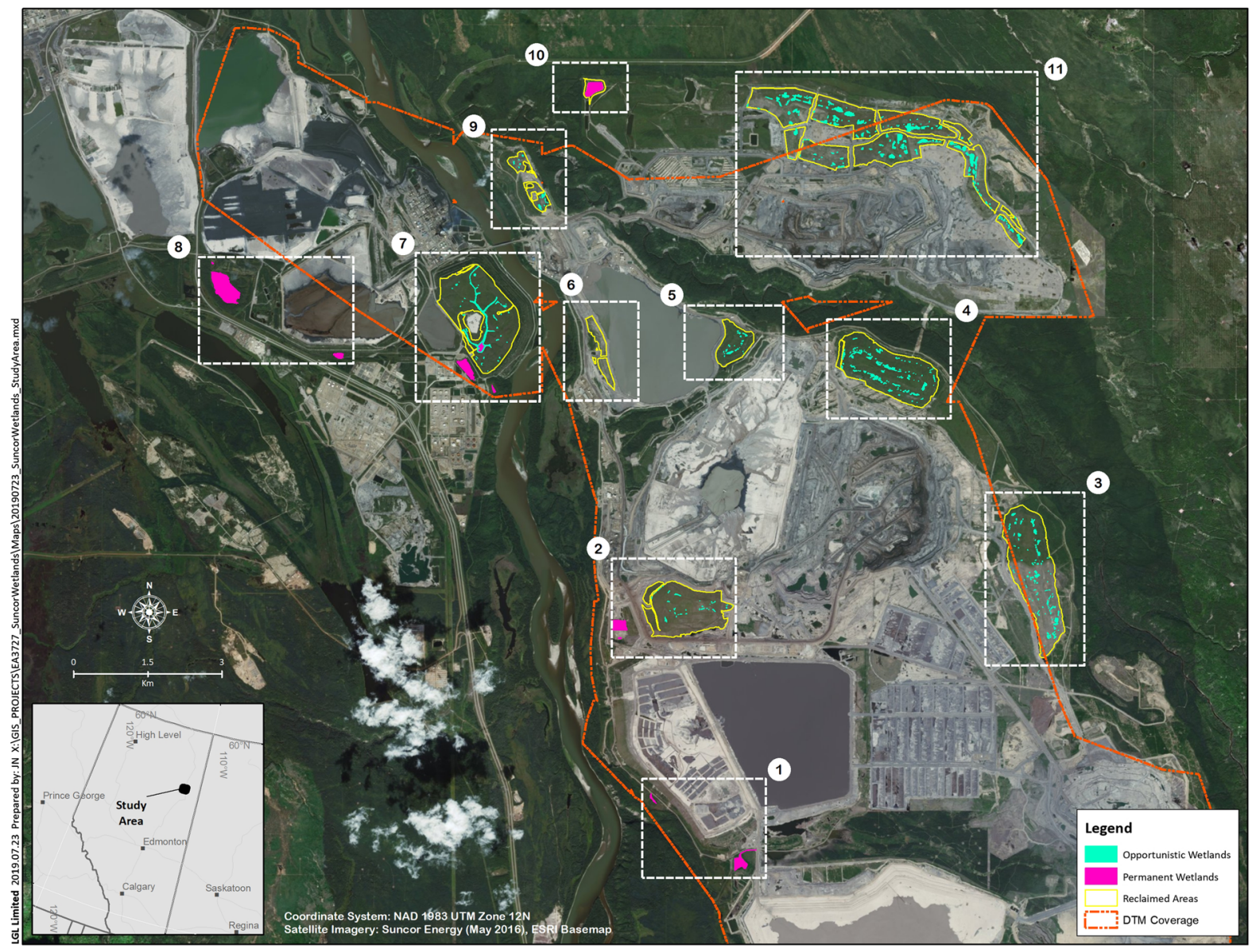

Fig. 1 The location of reclaimed areas (yellow outlines), permanent wetlands (pink polygons), opportunistic wetlands (green polygons) and digital terrain model (DTM) coverage within each of the 11 Areas of Interest on Suncor's Base Plant mine

The TWI was used to assign three wetness categories (low, medium, high) to areas with DTM coverage (Fig. 1). Category thresholds were determined from the mean and standard deviation of all TWI values. The mean was used to define the lowest wetness threshold (TWI values 4.71-5.12), the mean plus one half of the standard deviation defined the medium threshold (TWI values 5.12-5.54), and mean plus one standard deviation defined the upper (high) threshold (TWI values $>5.54$ ). TWI areas with values less than the mean were assigned a wetness category of nil. To delineate wetlands, the aerial photograph was displayed on screen using a colour infrared band (CIR) combination to highlight moisture and water bodies. Because the wetness index was used only as a visual aid and not to automate the delineation process, no comprehensive error analysis was undertaken. In areas without DTM coverage, desktop wetland delineation was accomplished using visual interpretation of the on-screen aerial imagery from September 2014; this method took more time but produced results similar to ones obtained for DTM coverage areas.

Opportunistic wetlands were preliminarily assigned to a wetland class of either shallow open water or marsh as per Alberta Environment and Sustainable Resource Development (AESRD 2015). Areas with darker, homogeneous pixels (i.e., visible standing water) were classified as shallow open water and areas with heterogeneous, dark pixels were classified as marshes. Ambiguous cases, where the wetland could not reliably be typed from the aerial imagery, were temporarily mapped as unspecified until they could be field verified. A fourth designation, intentionally reclaimed, was applied to constructed mineral wetlands. The same monthly satellite imagery was then used to determine the water permanence type (Alberta 

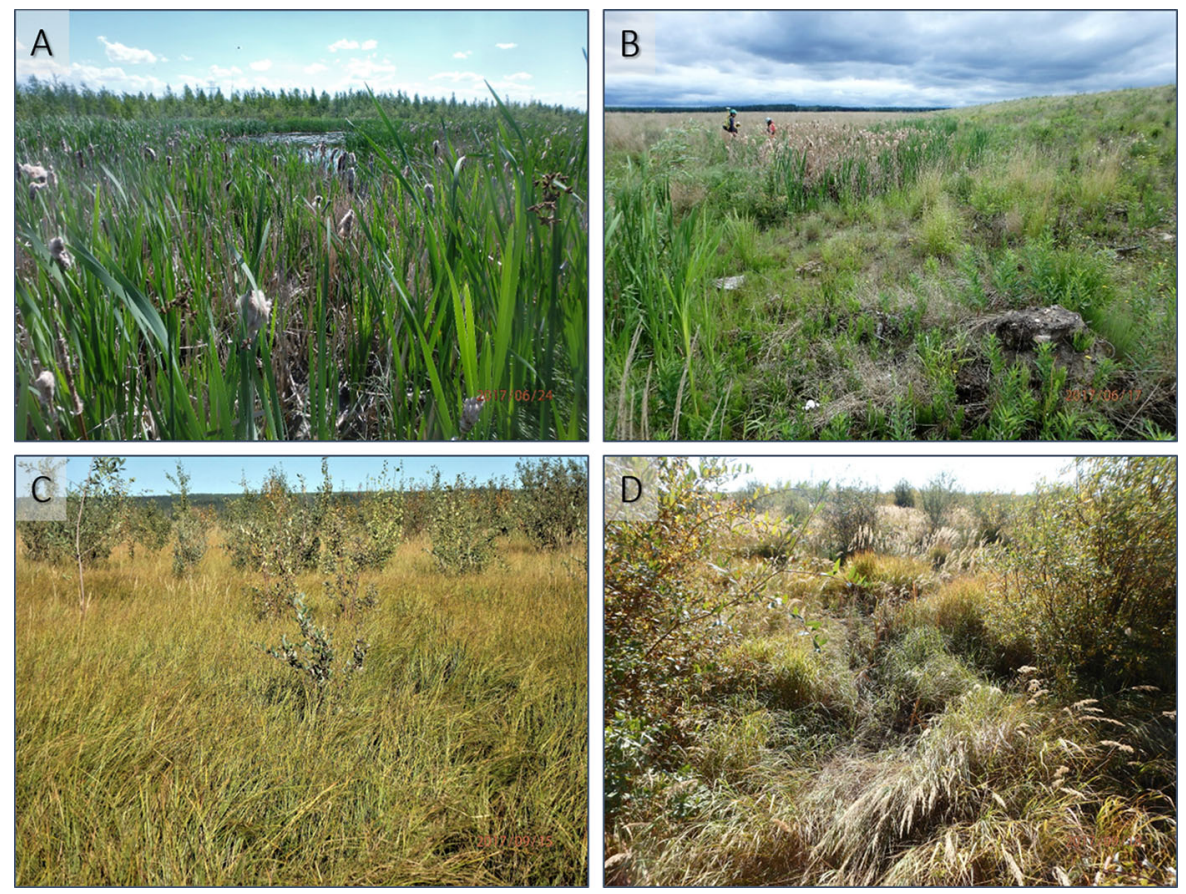

Fig. 2 Examples of opportunistic wetland habitat that has formed in the study area. a Shallow open water wetland with emergent vegetation, b seasonal marsh with obvious upland transition, $\mathbf{c}$ wet meadow zone at the edge of a seasonal marsh, and $\mathbf{d}$ shrubby swamp

Environment and Parks [AEP] 2014). Permanence was assessed two ways: (1) within-year permanence, or the number of weeks per year that a wetland was wet (Table 1); and (2) year-over-year wetted status, which was the number of years, between 2008 and 2015, that the wetland was wet. If a wetland was wet for $\geq 1 / 3 \mathrm{rd}$ of the years assessed, it was considered continuous; if wet for $<1 / 3$ rd of the years assessed, it was considered noncontinuous. If ponding occurred between May and November in year $t$ and continued to be observed in May of the following year, it was assumed that water was also present from December to April, although likely frozen and under snow. The results of the desktop exercise were used to plan and implement the field verification (phase 2).

\section{Phase 2: field verification}

From the dataset created in phase 1 (Novoa and Hawkes 2016), we selected a subsample of four intentionally reclaimed, and 100 opportunistic, wetland polygons to sample for field verification. After first stratifying by wetland type and permanence, the

Table 1 Wetland water permanence categories (from AEP 2014)

\begin{tabular}{lll}
\hline Water regime modifier & Weeks flooded & AWCS wetland type \\
\hline Temporary flooded & $1-4$ & Temporary (II) \\
Seasonally flooded & $5-17$ & Seasonal (III) \\
Semi-permanently flooded & $18-40$ & Semi-permanent (IV) \\
Intermittently exposed & $41-51$ & Intermittent (VI) \\
Permanently flooded & 52 & Permanent (V) \\
\hline
\end{tabular}

The Alberta Wetland Classification System (AWCS) wetland types were used to modify the classification of opportunistic and intentionally reclaimed wetlands assessed in this study 
proportion of total polygons per stratum was used to determine the target sample size by stratum. We used a Generalized Random Tessellation Stratified (GRTS; Stevens and Olsen 2004) approach to produce a spatially-balanced sample dataset in which the distribution of sample sites mimics the population spatial distribution while avoiding the creation of clumped sampling sites (Kincaid and Olsen 2016). Using GRTS also supports design-based inferences across the entire study area. Sampling effort was focused on AOIs with the highest concentrations of identified wetlands (Fig. 1) to minimize travel time while maximizing the number of unique wetland sites sampled. Field verification visits occurred in June and September 2017. A total of 238 phase 1 polygons were assessed, a number that exceeded the 100 initially selected for sampling (Table 2) because many mapped polygons turned out to be part of a single larger wetland complex when delineated in the field. Consequently, multiple polygons were often captured within a single field delineation. At each sample location, the desktop-identified feature was confirmed to be wetland or not wetland based on hydroregime and vegetation indicators. Each confirmed wetland was classified as to class, form, and permanency type using keys in AESRD (2015) and AEP (2014). At all subsample locations, vegetation and (if needed) soil assays were completed to identify the point at which the wetland ended, and the upland habitat began. For wetlands that had high topographic relief or obvious transitions in vegetation from wetland to upland, vegetation alone was used to verify the desktop interpretation of the wetland boundary. In contrast, wetlands with gentle relief and shallow shorelines tended to have transitional plant communities containing a mix of both wetland and upland species, especially towards the outer extent of the wetland. In these instances, a combination of soil and vegetation indicators was used to determine the true wetland extent (Government of Alberta 2015).

Vegetation structure and composition were assessed within $5.64 \mathrm{~m}$-radius $\left(100 \mathrm{~m}^{2}\right)$ circular plots at one or more representative points around the suspected wetland perimeter. The number of points sampled was determined by the complexity of the site; heterogeneous wetlands with multiple community types required a higher sampling rate than more homogenous sites. At each point, a series of circular plots extending across both sides of the suspected wetland boundary was rapidly assessed to pinpoint the precise wetland extent using vegetation indicators identified in Government of Alberta (2015).

Assessments were repeated as the surveyor moved upslope until wetland indicators were replaced by

Table 2 Number and total area (ha) of desktop-identified features per wetland class and water permanence type on the Suncor's Base Plant mine

\begin{tabular}{|c|c|c|c|c|c|}
\hline Wetland class & Origin & Water permanence type & $\mathrm{N}$ (no. polygons) & Area (ha) & n (samples) \\
\hline \multirow[t]{3}{*}{ Unspecified $^{\mathrm{a}}$} & \multirow[t]{3}{*}{ Opportunistic } & Seasonal (III) & 79 & 3.0 & 10 \\
\hline & & Semi-permanent (IV) & 197 & 2.2 & 25 \\
\hline & & Temporary (II) & 7 & 0.1 & 1 \\
\hline \multirow[t]{3}{*}{ Marsh } & \multirow[t]{3}{*}{ Opportunistic } & Intermittent (VI) & 8 & 1.0 & 1 \\
\hline & & Seasonal (III) & 12 & 0.6 & 2 \\
\hline & & Semi-permanent (IV) & 70 & 10.7 & 9 \\
\hline \multirow[t]{3}{*}{ Shallow open water } & \multirow[t]{3}{*}{ Opportunistic } & Intermittent (VI) & 16 & 6.1 & 2 \\
\hline & & Seasonal (III) & 1 & 0.1 & 1 \\
\hline & & Semi-permanent (IV) & 283 & 17.9 & 35 \\
\hline Shallow open water or Marsh & Intentionally reclaimed & Permanent (V) & 14 & 48.3 & 14 \\
\hline Total & & & 687 & 89.9 & 100 \\
\hline
\end{tabular}

$N$ number of polygons corresponding to each type, $n$ (samples) number of polygons initially designated for field verification. Wetland permanence modifiers follow AEP (2014)

${ }^{a}$ Temporary designation used (prior to field verification) for opportunistic wetlands that could not reliably be classified from remote imagery as either shallow open water or marsh 
predominantly non-wetland indicators, indicating that the landward extent of the wetland had been reached. This transition point was marked with GPS and temporarily flagged to help guide the subsequent GPS delineation. To provide a permanent data record of the wetland versus non-wetland condition near the wetland boundary, detailed structural and compositional information on two plots, one immediately below the demarcation line, and one immediately above the demarcation line, was recorded using a modified version of the field form in Government of Alberta (2015; App. 7). A total of $72100 \mathrm{~m}^{2}$ detailed vegetation plots were sampled near the outskirts of delineated wetlands (including intentional reclaimed wetlands) across the entire study area.

If necessary, soil properties were examined on both sides of the suspected wetland:upland boundary to aid in pinpointing the precise wetland extent. A separate soil core was taken at the approximate centre of each vegetation plot to look for evidence of primary soil indicators (Government of Alberta 2015). These primary soil indicators included characteristics of water-altered or hydric soils such as gleying or mottling; presence of organic soils or organic horizons; presence of peat; oxidized rhizospheres, mineral accretions, or sulphuric odors; remains of aquatic invertebrates; and other soil properties associated with a prolonged seasonally high water table (Government of Alberta 2015). If any primary soil indicators of a wetland were present, the area was recorded as wetland. If neither vegetation nor soil indicators were present, the area was recorded as non-wetland.

To assess if plant community composition (presence/absence and percent cover) differed between different reclamation areas and between wetland sites within locations both above and below the wetland perimeter, we used permutational multivariate analysis of variance (PERMANOVA) in combination with non-metric multidimensional scaling (nMDS) plots. Wetland community development relative to prevailing soil properties was likewise assessed for that subset of wetlands for which soil information was available. Data analyses were performed in PRIMER with the PERMANOVA add-on (Anderson et al. 2008; Clarke and Gorley 2015). nMDS was used with 100 restarts (Clarke 1993), and the response variables for nMDS plots were resemblance matrices calculated using Bray-Curtis coefficients (Clarke 1993) constructed from vegetation species composition data. All plots had a stress (goodness of fit) $\leq 0.2$ and were considered good 2-dimensonal representations of higher dimensional trends (Clarke 1993).

Where ponded water was present, water physicochemical properties ( $\mathrm{pH}$, dissolved oxygen [DO; $\mathrm{mg}$ / $\mathrm{L}]$, conductivity $[\mu \mathrm{S} / \mathrm{cm}]$, and temperature $\left[{ }^{\circ} \mathrm{C}\right]$ ) were measured $30 \mathrm{~cm}$ below the surface. DO, conductivity, and temperature were collected using a YSI Professional Series 2030 Multi-function Metre (Model Pro2030). An Oakton waterproof pHTester 30 was used to measure $\mathrm{pH}$.

Wetland perimeters were georeferenced in the field using a Trimble ${ }^{\circledR}$ GPS unit with sub-metre GPS accuracy. If the field delineation was within $\pm 5 \mathrm{~m}$ of the desktop delineation, the desktop delineation was considered verified (Government of Alberta 2015). To characterize internal vegetation zonation patterns, one to several supplementary transects were run from the centres of a selection of sampled wetlands uphill as far as the upland interface (or, in some cases, oriented so as to traverse a mosaic of wetland/upland habitats). Detailed, running plant species lists were recorded along each transect. Any evident transition points between vegetation zones (e.g., wet meadow and emergent); between different wetland classes (e.g., marsh and swamp); or between wetland and upland habitat, were georeferenced. A total of 188 supplementary transects were sampled. Once mapped, these transitions, in combination with the delineated wetland boundaries, served as a useful visual aid during subsequent orthophoto interpretations (Fig. 3).

Field-verified wetland areas were compared to aerial estimates from the desktop exercise to assess the accuracy of the latter. Observed differentials between the two delineation exercises were then used to extrapolate across areas that had not been fieldverified to derive estimates of total wetland extent for each AOI. Extrapolations were made by weighting the desktop estimate for each AOI (equating to the total area of all mapped polygons) by a correction factor (CF). The CF was calculated by dividing the total wetland delineated area (desktop wetland area verified + additional wetland area field-delineated) by the desktop identified wetland area. The corrected total wetland area (ha) was calculated by multiplying the desktop-identified wetland (ha) by the CF. The total area of opportunistic wetlands was then estimated by summing the individual corrected values over all AOI (Table 6, "Results"). The CF provides an estimate of 


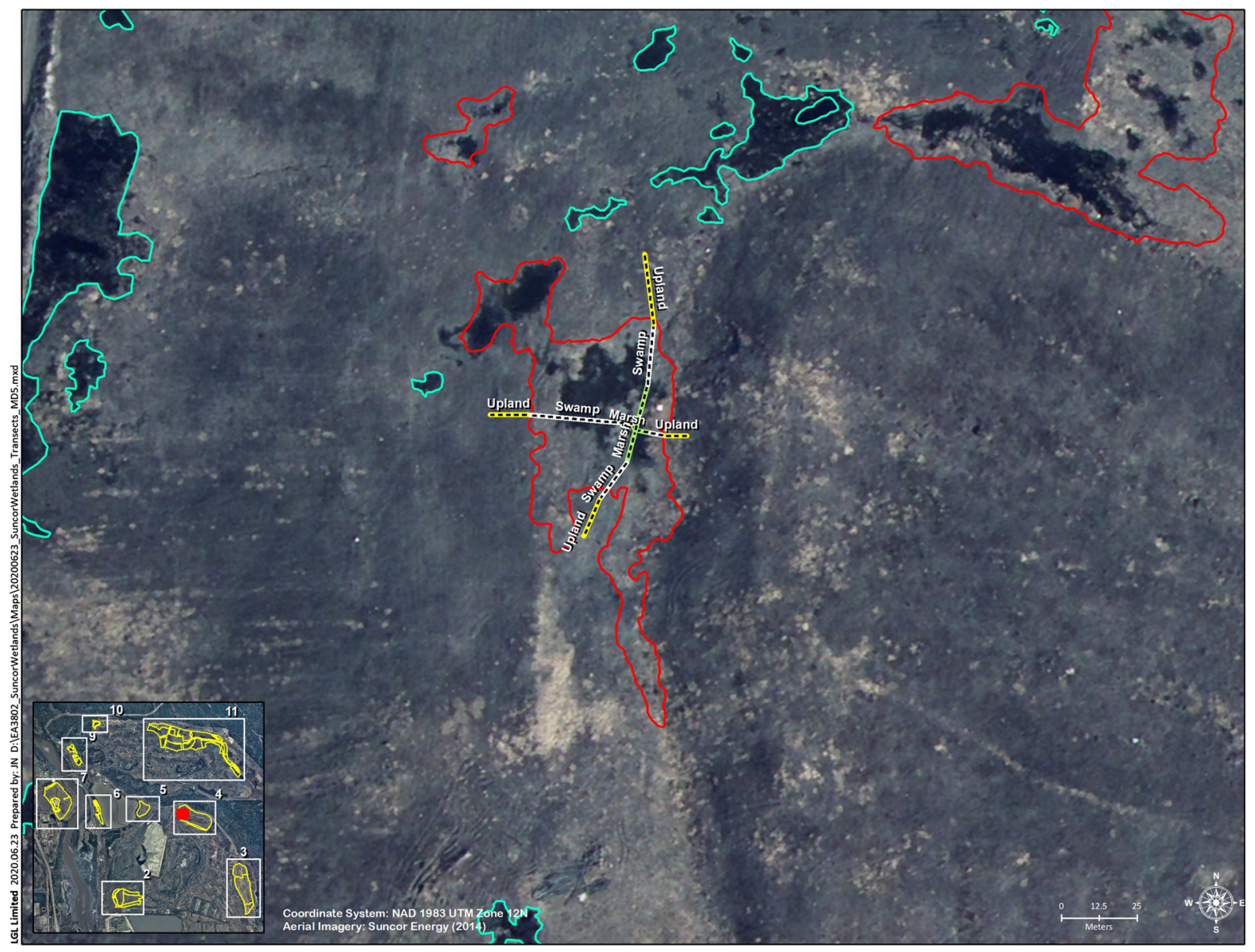

Fig. 3 Example transect from a field-delineated, opportunistic wetland complex in area of interest (AOI) 4 (Fig. 1) showing transitions between shallow marsh, shrubby swamp, and upland

the extent of wetlands in areas where field verification did not occur. As such, field verification is needed to produce a more accurate estimate of the extent of wetlands in those areas.

\section{Results}

\section{Phase 1}

Prior to this study, Suncor had independently delineated 48.0 ha of intentionally reclaimed wetlands at its Base Plant mine. During the desktop exercise, a total of 687 polygons representing 41.9 ha of opportunistic wetlands $(\sim 3.5 \%$ of the area assessed) were mapped (Table 2). Wetlands were assigned to one of two wetland classes, marsh $(n=90)$ or shallow open water habitat. Red polygons represent the field-verified perimeters; turquoise aligns with the desktop delineations

( $n=300)$, or else left as "unspecified" $(n=283)$. The remaining 14 wetlands were classified as intentionally reclaimed (Table 2). Further typing for water permanence yielded nine different mapping categories for opportunistic wetlands, plus one category for intentionally reclaimed wetlands (Table 2). Based on the monthly satellite imagery, most marshes $(n=70)$, all shallow open water $(n=283)$, and the majority of unspecified wetlands $(n=197)$ were assessed as having a water permanence type of semi-permanent (Table 2). On a year-over year basis, all assessed marsh and shallow open water areas, and most unassigned wetlands (78\%), were continuously inundated through the study period (2008-2015; Table 3). Noncontinuous (i.e., those wetlands wetted for $<1 /$ 3rd of the years assessed) occupied 2.37 ha or $\sim 6 \%$ 
of the total wetland area assessed for year-over-year continuity (Table 3).

\section{Phase 2}

Field delineations

Confirmed wetlands fell into one of three wetland classes (AESRD 2015): shallow open water, marsh (shallow form), or swamp (shrubby form). In cases where shallow open water was identified, this class generally formed a subcomponent within a larger area of marsh. Shallow open water was generally limited in extent and could either support minor amounts of submersed and/or floating aquatic vegetation or be unvegetated. Based on conductivity readings (AESRD 2015), standing water ranged from slightly brackish to moderately brackish, with $\mathrm{pH}$ ranging from 7.2 to 8.7. In contrast to the desktop prediction (Table 2), fieldverified shallow open water wetlands tended to be of seasonal duration, while only a few were classed as semi-permanent.

Of the 238 polygons field-verified, seven were reclassified as non-wetland following field inspection, representing $2.9 \%$ of the polygons sampled. The misidentified features included dry swales, dried up mud depressions, dry ravines, and wood debris pilesfeatures that, in the desktop analysis, presented as regions of darker pixelation compared to the surrounding area. The remaining 231 locations were verified as classifiable wetlands (or parts of wetlands). Of these, $80.8 \%$ of the originally unspecified wetlands were classed as marsh, $7.0 \%$ were classed as shallow open water, and $12.3 \%$ were classed as swamp. Of those initially mapped as marsh, $4.7 \%$ were reclassified as shallow open water and $1.4 \%$ were reclassified as swamp. Of those mapped as shallow open water, $37.5 \%$ were reclassified as marsh and $1.8 \%$ were reclassified as swamp (Table 4).

With respect to water permanency typing, most $(88.5 \%)$ unspecified wetland area was verified as seasonal during ground surveys, with $3.7 \%$ of this area identified as temporary and $3.7 \%$ identified as semipermanent (Table 5). Most (86.1\%) of the area identified in the desktop exercise as temporary was also retyped as seasonal, along with $\sim 15 \%$ of the area initially typed as semi-permanent (Table 5). Overall, $86 \%$ of the area covered by water decreased significantly between June and September and in most cases surface water was completely absent by September. Assuming these observations are reflective of normal seasonal variation, they support the prediction that desktop estimations of standing water based on aerial photo interpretation will be influenced by acquisition date (both month and year) of the aerial photos used (Novoa and Hawkes 2016).

The desktop analysis was successful $96 \%$ of the time in identifying the presence of marshes and shallow open water wetlands (Miller et al. 2017).

Table 3 Number of desktop-identified opportunistic wetlands and area by wetland class and year-over-year wetted status

\begin{tabular}{|c|c|c|c|}
\hline Desktop-identified opportunistic wetlands & Count & Proportion $(\%)$ & Area (ha) \\
\hline \multicolumn{4}{|l|}{ Unspecified $^{\mathrm{a}}$} \\
\hline Continuous & 221 & 78 & 2.86 \\
\hline Noncontinuous & 62 & 22 & 2.37 \\
\hline \multicolumn{4}{|l|}{ Marsh } \\
\hline Continuous & 90 & 100 & 12.27 \\
\hline Noncontinuous & 0 & 0 & 0 \\
\hline \multicolumn{4}{|l|}{ Shallow open water } \\
\hline Continuous & 300 & 100 & 24.06 \\
\hline Noncontinuous & 0 & 0 & 0 \\
\hline Total & 673 & & 41.6 \\
\hline
\end{tabular}

Continuous: wetted (inundated) for $\geq 1 / 3$ rd of the years assessed. Noncontinuous: wetted for $<1 / 3$ rd of the years assessed

${ }^{a}$ Temporary designation used (prior to field verification) for opportunistic wetlands that could not reliably be classified from remote imagery as either shallow open water or marsh 
Table 4 Changes in classification of desktop-identified features following field verification, expressed as area percentages of the initial classification

\begin{tabular}{llccc}
\hline Desktop-identified feature & \multicolumn{4}{l}{ Field-delineated area as \% of desktop-identified area (ha) } \\
\cline { 2 - 5 } & Marsh (\%) & Swamp (\%) & Shallow open water $(\%)$ & Not wetland (\%) \\
\hline Unspecified & 80.8 & 12.3 & 7.0 & 0 \\
Marsh & 93.8 & 1.4 & 4.7 & 0.1 \\
Shallow open water & 37.5 & 1.8 & 60.8 & 0 \\
\hline
\end{tabular}

E.g., $93.8 \%$ of the area identified in the desktop exercise as marsh was verified as marsh, 1.4\% was reclassified as swamp, etc.

Table 5 Changes in typing of desktop-identified water permanence type following field verification, expressed as area percentages of the initial typing

\begin{tabular}{lcccc}
\hline Desktop-identified water permanence type & \multicolumn{4}{l}{ Field-delineated area as \% of desktop-identified area (ha) } \\
\cline { 2 - 5 } & Temporary (\%) & Seasonal (\%) & Semi-permanent (\%) & Not assessed (\%) \\
\hline Unspecified & 3.7 & 88.5 & 3.72 & 0.9 \\
Temporary & 13.9 & 86.1 & 0 & 0 \\
Seasonal & 1.8 & 97.8 & 0.3 & 0.1 \\
Semi-permanent & 2.6 & 14.8 & 79.5 & 3.7 \\
\hline
\end{tabular}

For example, $13.9 \%$ of the area identified in the desktop exercise as temporary was verified as temporary, $86.1 \%$ was reclassified as seasonal, etc.

However, wetland aerial extents were consistently underestimated by the desktop delineations. The underestimation percentage ranged from $\sim 35 \%$ for AOI 9 up to $\sim 98 \%$ for AOI 2 , with an overall underestimation rate of $\sim 89 \%$ for all areas sampled. Polygons delineating non-inundated wetland habitat had a median underestimation of $\sim 78 \%$, while those delineating standing water (including emergent and shallow open water zones) had a median underestimation of $\sim 16 \%$. Differentials were due in part to underestimations in the extent of non-inundated vegetation zones (e.g., wet meadows) associated with marsh and shallow open water wetlands, and in part to the under-detection of shrubby swamps. The latter, of which $\sim 59$ ha were identified and mapped during fieldwork, were non-ponded areas of elevated soil moisture content supporting a plant cover dominated by obligate or facultative wetland shrubs (e.g. Salix bebbiana, Alnus viridis ssp. crispa, Populus balsamifera) and grasses (e.g. Calamagrostis canadensis), with a sparse component of obligate wetland sedges (e.g., Carex aquatilis and C. utriculata) and various facultative upland species. This widespread wetland class formed a component of 71 field-verified polygons, representing $\sim 30 \%$ of the 238 polygons surveyed.

The total area of opportunistic wetlands delineated during the phase 1 desktop exercise per AOI was between 0.65 and 22.93 ha, for a total of 41.9 ha across AOIs (Table 6). Field verifications (phase 2) led to the delineation of an additional 0.09 to 29.82 ha (total of $\sim 65.8$ ha) across AOIs. Combining the two results, between 0.19 and 30.43 ha of opportunistic wetlands were delineated per AOI for a total of 74.0 ha. Extrapolating across unsampled areas, corrected estimates for individual AOIs were between 1.3 ha (AOI 9 in Fig. 1) and 95.5 ha (AOI 11 in Fig. 1), resulting in an overall estimate for Suncor's Base Plant mine of $\sim 210$ ha (Table 6). The relatively high CF obtained for AOI 2 (49.7) was related to the identification in the desktop exercise of what appeared to be several small, distinct wetlands. Field verifications revealed these isolated areas to be mostly patches of open water nested within a much more extensive area of swamp and marsh (as determined by vegetation and soil sampling) not readily detected in the remote imagery. The total area mapped as opportunistic wetland habitat represents $\sim 17.4 \%$ of 
Table 6 Estimated opportunistic wetland coverage by area of interest (AOI) on the Suncor Base Plant mine

\begin{tabular}{|c|c|c|c|c|c|c|}
\hline \multirow[t]{2}{*}{ AOI } & \multirow{2}{*}{$\begin{array}{l}\text { Phase } 1 \\
\text { Desktop-identified } \\
\text { wetland (ha) }\end{array}$} & \multicolumn{3}{|l|}{ Phase 2} & \multicolumn{2}{|c|}{ Correction } \\
\hline & & $\begin{array}{l}\text { Phase } 1 \text { wetland field- } \\
\text { sampled (ha) }\end{array}$ & $\begin{array}{l}\% \\
\text { sampled }\end{array}$ & $\begin{array}{l}\text { Additional wetland field- } \\
\text { delineated (ha) }\end{array}$ & $\mathrm{CF}$ & $\begin{array}{l}\text { Corrected total wetland } \\
\text { area (ha) }\end{array}$ \\
\hline 2 & 0.65 & 0.61 & 93.8 & 29.82 & 49.71 & 32.1 \\
\hline 3 & 4.61 & 2.33 & 50.5 & 19.77 & 9.48 & 43.8 \\
\hline 4 & 5.63 & 1.43 & 25.4 & 3.43 & 3.4 & 19.1 \\
\hline 5 & 0.89 & 0.61 & 68.5 & 3.57 & 6.85 & 6.1 \\
\hline 7 & 6.3 & 0.1 & 1.6 & 0.09 & 1.91 & 12.1 \\
\hline 9 & 0.86 & 0.34 & 39.5 & 0.19 & 1.55 & 1.3 \\
\hline 11 & 22.93 & 2.82 & 12.3 & 8.91 & 4.16 & 95.5 \\
\hline Total & 41.9 & 8.2 & & 65.8 & & 210.0 \\
\hline
\end{tabular}

The proportion of each AOI sampled during fieldwork is shown along with the correction factor (CF), which was calculated by dividing the total Phase 2 delineated area (Phase 1 area sampled + additional wetland area field-delineated) by the original Phase 1 area. E.g., for AOI 2: $(0.61+29.82) / 0.61=49.71$. The corrected total wetland area (ha) was calculated by multiplying the desktopidentified wetland (ha) by CF (e.g., for AOI 2 : $0.65 \times 49.71=32.1$ )

the overall area considered (1209 ha) — an increase of $>400 \%$ over the total wetland area (including intentionally constructed wetlands) recognized for the mine site prior to this study (i.e., 48 ha). Of the opportunistic wetlands delineated, most $(n=617)$ were $<1$ ha in area (Fig. 4). Of those $>1$ ha $\left(10,000 \mathrm{~m}^{2}\right)$, only 12 exceeded 5 ha (Fig. 4).

\section{Community composition}

On-the-ground vegetation mapping helped inform the subsequent refinements to desktop mapping and delineation, while the permutational analysis of variance highlighted some of the possible environmental factors influencing developmental trajectories at

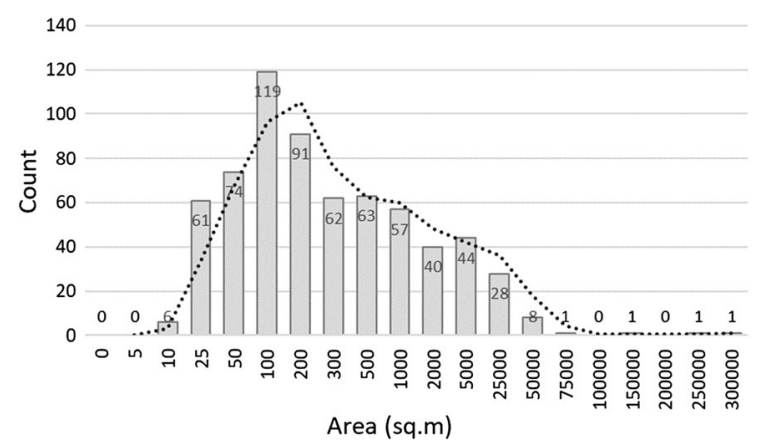

Fig. 4 Area distribution of mapped opportunistic wetlands (desktop-identified + field-delineated) on habitats reclaimed to an upland landform on Suncor's Base Plant mine in northeastern Alberta different locations across the study area. Overall, we recorded 95 distinct plant species along wetland transects. Of these, 49 were characterized as either obligate wetland or facultative wetland plants. Abrupt transitions between wetland and upland habitats were typically indicated by the existence of distinct species assemblages upslope and downslope of the putative wetland:upland boundary. Above the boundary, upland vegetation was indicated by a predominance of facultative or facultative upland herbs (both native and non-native) and shrubs, such as Vicia cracca, Sonchus arvensis, Arctostaphylos uva-ursi, Astragalus cicer, Crepis tectorum, Bromus ciliatus, Elymus trachycaulis ssp. trachycaulis, Leymus innovatus, Shepherdia canadensis, Rubus idaeus, and Ribes oxyacanthoides. Below the boundary, the presence of certain obligate wetland species such as Typha latifolia, Carex aquatilis, Salix planifolia, S. exigual interior, Schoenoplectus acutus, and Equisetum fluviatile, particularly if two or more of these occurred in combination, was generally a reliable indicator of wetland habitat.

The specific plant compositions recorded on either side of the wetland boundary varied among AOIs (Fig. 1). This variation can be seen in the segregation of plant cover data by AOI, when samples from the two habitat types (upland and wetland) are plotted separately with nMDS ordinations (Fig. 5). For example, Wapisiw (AOI 7), MD5 (AOI 4), and NSE (AOI 11) samples form a distinct cluster on the left, right, 
and bottom regions of the upland diagram, respectively (Fig. 5a). In the wetland diagram, MD5 and NSE samples cluster at the top and bottom, respectively, with MD2 and MD8 (AOI 3) samples clustering closely (but still separately) near the middle (Fig. 5c). The variation in vegetation species composition among sites was statistically significant (Table 7), suggesting that wetland development is sensitive to the specific substrates used during the reclamation process.
Differences in wetland community development among the AOIs are associated with topographic variation (e.g., elevation and \% slope) in combination with the specific reclamation substrates that were placed over tailings prior to seeding/planting (Fig. 6). Of the various abiotic parameters modeled (e.g., soil class, surface material, horizon depths [upper/lower], drainage, aspect, slope, and elevation), the most influential variables on community composition were soil class and surface material. For example, presence of Rego Gleysol and Rego Humic Gleysol (R.G and

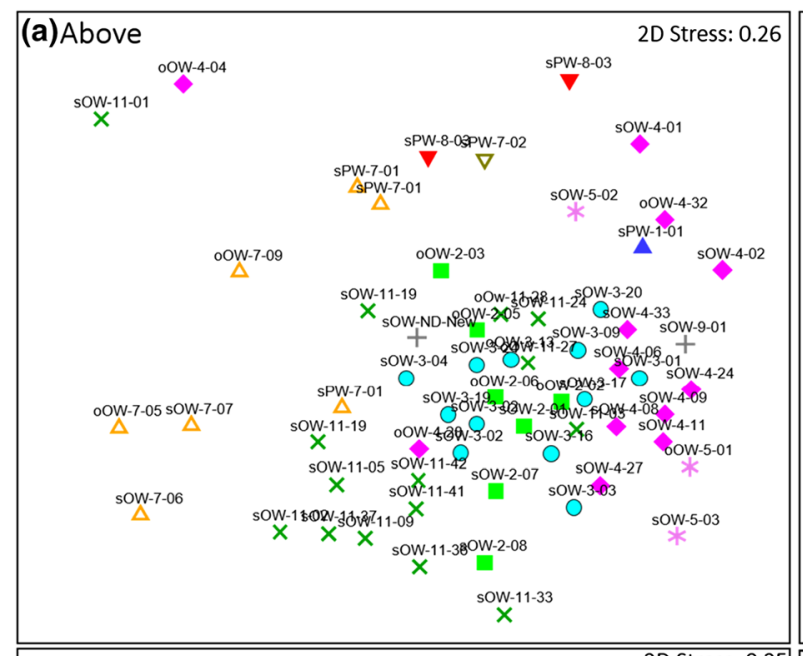

(b) Above

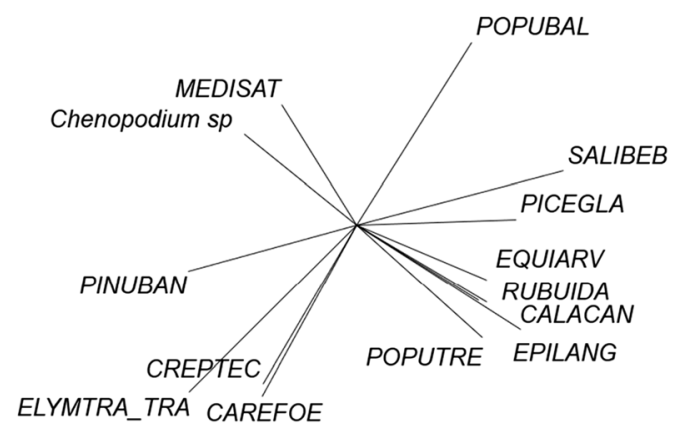

(c) Below sow- $2 \mathrm{D}$ Stress: 0.25

(d) Below
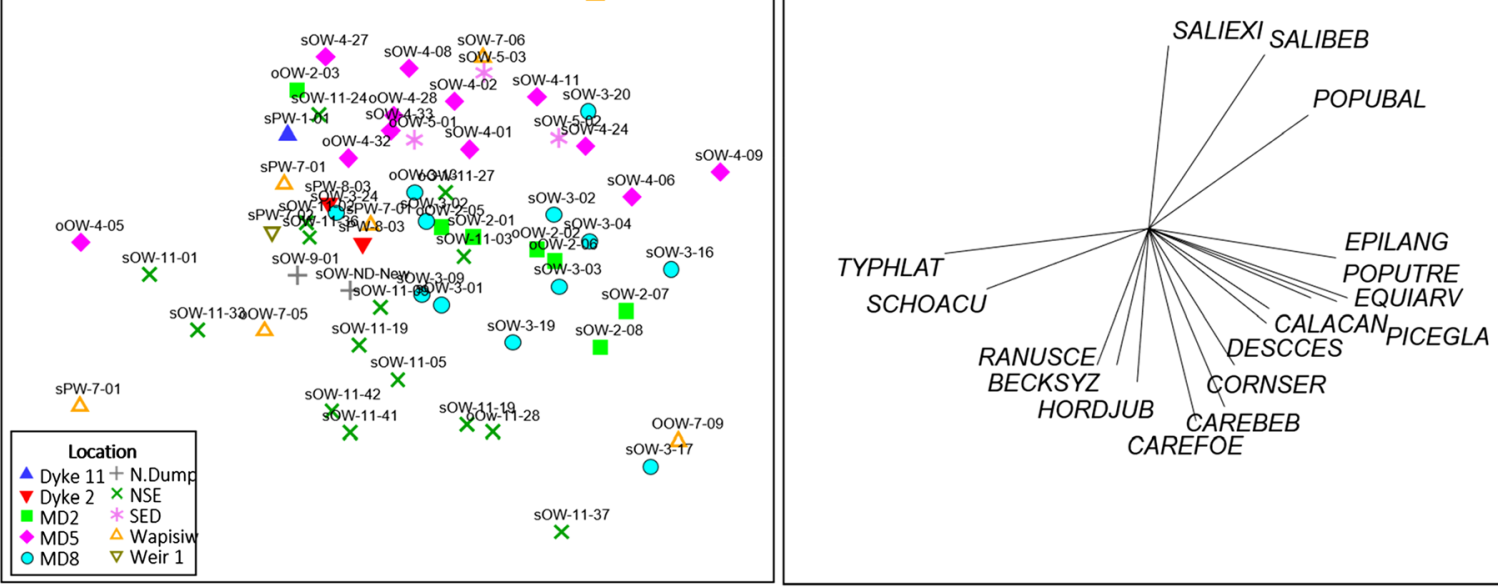

Fig. 5 nMDS (non-metric multidimensional scaling) plots (a and c) of plant species composition showing differences between plant communities between sites and reclamation areas. b and $\mathbf{d}$ are vector overlays (Pearson correlation coefficient $=0.4$ or greater), showing which plant species are responsible for observed differences in composition. The two upper panels (a and $\mathbf{b}$ ) correspond to upland sites, and the two

lower panels (c and d) correspond to wetland sites. Intentionally reclaimed wetlands: Dyke 2 (AOI 8), Dyke 11 (AOI 1), Wapisw (AOI 7), Weir 1 (AOI 7). Opportunistic wetland locations: MD2 (AOI 2), MD5 (AOI 4) MD8 (AOI 3), N.Dump (AOI 9), NSE (AOI 11), SED (AOI 5). Species are indicated by their 7-letter Nature Serve species code 
Table 7 Permutational multivariate analysis of variance (PERMANOVA) table showing the variation in plant community composition (presence/absence and percent cover) between different reclamation areas (AOIs; fixed factor) and sampled wetland polygons (nested within area; random factor) above and below the wetland perimeter

\begin{tabular}{|c|c|c|c|c|c|c|}
\hline Source & df & MS & Pseudo-F & Unique permutations & $p$ & Variance components $(\%)$ \\
\hline \multicolumn{7}{|l|}{ (a) Upland } \\
\hline Area (AOI) & 9 & 5174.50 & 2.59 & 9825 & 0.0001 & 23.7 \\
\hline Polygon (Area) & 47 & 1906.80 & 1.34 & 9874 & 0.13 & 18.4 \\
\hline Residual & 5 & 1426.20 & - & - & - & 57.9 \\
\hline Total & 61 & - & - & - & - & - \\
\hline \multicolumn{7}{|l|}{ (b) Wetland } \\
\hline Area (AOI) & 9 & 4631.50 & 2.16 & 9804 & 0.0001 & 18.4 \\
\hline Polygon (Area) & 47 & 2055.50 & 1.29 & 9888 & 0.17 & 17.7 \\
\hline Residual & 5 & 1589.40 & - & - & - & 63.9 \\
\hline Total & 61 & - & - & - & - & - \\
\hline
\end{tabular}

Variance components represents the percent of the observed community variation accounted for by each factor. Significant variables are denoted in bold
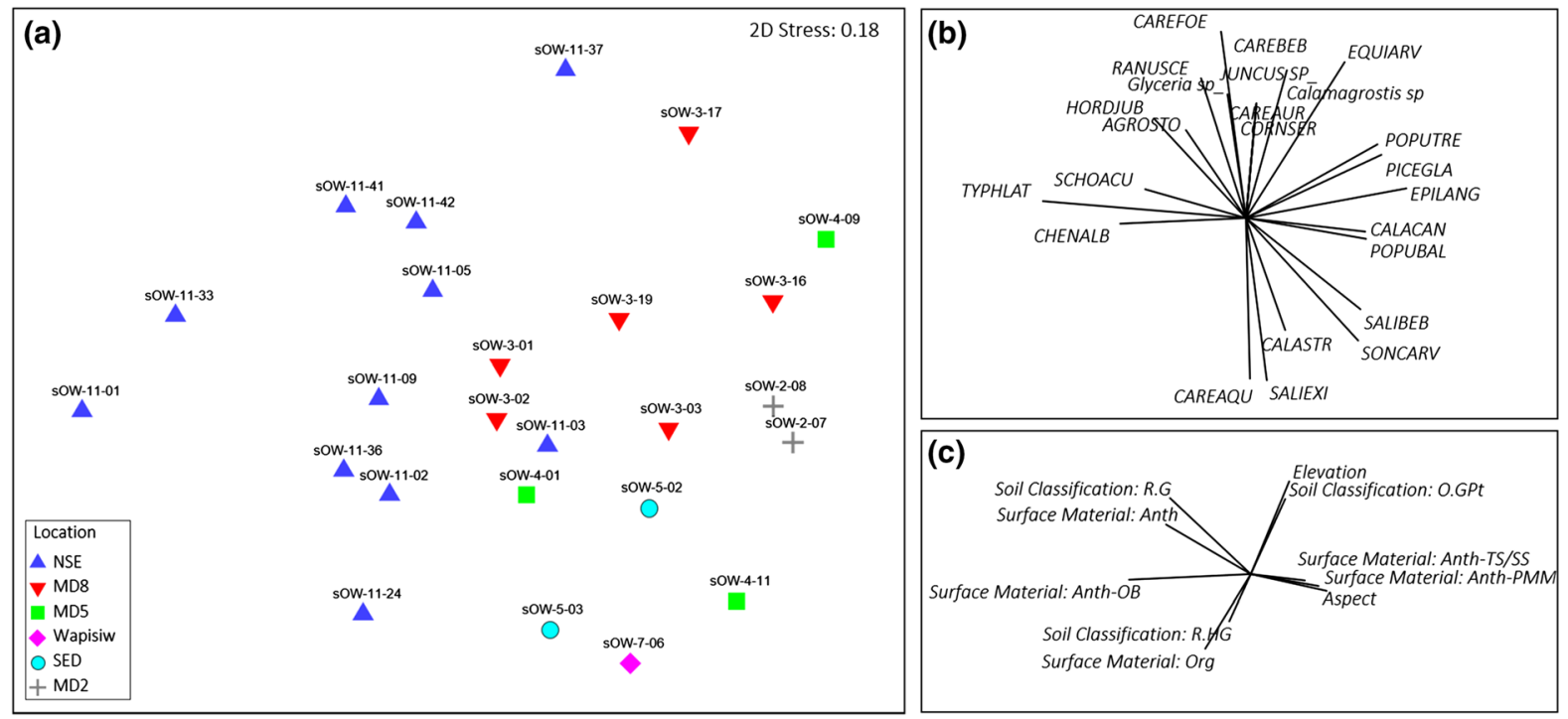

Fig. 6 nMDS (non-metric multidimensional scaling) plot (a) of the subset of plant community data associated with soil pits. b Vector overlay (Pearson correlation coefficient $=0.4$ or greater), showing which species are associated with the observed variation in community composition. c Second vector overlay showing (Pearson correlation coefficient 0.2 ) which soil parameters are associated with variation in community composition. $R G$ Rego Gleysol, R.HG Rego Humic Gleysol, Anth-OB

R.HG, in combination with anthropogenically redeposited surface materials such as Anthropogenicoverburden placed soil [Anth-OB]), is correlated with cover of obligate wetland species such as Typha anthropogenic-overburden placed, O.Gpt Orthic Gleysol peaty, Anth-TS/SS anthropogenic-topsoil/subsoil placed, Anth-PMM anthropogenic-peat mineral mix placed. Intentionally reclaimed wetlands: Dyke 2 (AOI 8), Dyke 11 (AOI 1), Wapisw (AOI 7), Weir 1 (AOI 7). Opportunistic wetland locations: MD2 (AOI 2), MD5 (AOI 4) MD8 (AOI 3), N.Dump (AOI 9), NSE (AOI 11), SED (AOI 5). Species are indicated by their 7-letter Nature Serve species code

latifolia (TYPHLAT) and Schoenoplectis acutus (SCHOACU). On the other hand, Orthic Gleysol peaty (O.Gpt), Anthropogenic-topsoil/subsoil placed (Anth-TS/SS), and Anthropogenic-peat mineral mix 
placed (Anth-PMM) tend to be associated with more transitional (facultative) wetland plant associations (e.g., Calamagrostis canadensis and Salix bebbiana; Fig. 6).

\section{Discussion}

Field surveys in 2017 confirmed the finding of Novoa and Hawkes (2016) that reclamation areas on Suncor Base Plant support an abundance of opportunistic wetland habitat. We estimate that $\sim 210$ ha of wetlands (a combination of shallow open water, marshes, and swamps) have spontaneously developed on reclaimed upland landforms at the mine, representing $\sim 17 \%$ of the 1,209 ha considered in this study and a greater than four-fold increase over the total wetland area (including intentionally constructed wetlands) recognized for the mine site prior to this study. The proportion of area comprising opportunistic wetlands on Suncor's Base Plant was greater than that reported for Syncrude's Mildred Lake Lease ( $\sim 8 \%$ ) although the methods used to assess wetland occurrence and distribution at Syncrude differed (Little-Devito et al. 2019).

While the desktop (remote sensing) exercise used for phase 1 of this study was successful at predicting the existence of wetland conditions on the ground over $96 \%$ of the time, it was less successful at predicting the spatial extent of those wetlands. Wetland extents were consistently underestimated by the desktop delineations, due mainly to underestimations in the extent of non-inundated vegetation zones (e.g., wet meadow) as well as shrubby swamp. Polygons indicating noninundated wetland habitat had a median underestimation of $\sim 78 \%$, while those delineating standing water (including emergent and shallow open water zones) had a much smaller, median underestimation of $\sim 16 \%$. The accuracy of desktop delineations may also have been affected by differences in acquisition dates among the aerial photos, digital elevation model (DEM), and field samples, and by the resolution of the existing DEM. The lack of a suitable available method for calibrating the topographic wetness index (TWI) was likely also a factor affecting mapping accuracy (Novoa and Hawkes 2016). Further explorations with GIS approaches could yield improvements to the desktop methodology. For example, the inclusion of other topographic indexes such as the downslope distance gradient (Hjerdt et al. 2004) could increase the accuracy of wetland detection and delineation. A cursory examination of juxtaposed examples of the TWI and the downslope index, applied to the same opportunistic wetlands at MD2, suggest that the two indices could play a complementary role in identifying wetland locations and extents (Miller et al. 2017). Additional investigations are needed to determine if these different indices can be calibrated with each other in a way that improves wetland detectability (Miller et al. 2017).

Terrestrial and emergent plant communities inhabiting opportunistic and intentionally reclaimed wetlands at Suncor's Base Plant mine were comparable, in terms of vegetation structure, species composition, and species richness, to naturally occurring mineral wetlands in the region (AESRD 2015; Miller et al. 2017). However, submersed and floating-leaved plant communities (e.g., Ceratophyllum demersum and Potamogeton/Nuphar communities) were generally poorly developed to absent in the opportunistic shallow open water wetlands we surveyed (albeit from a distance, as we were not boat-equipped). Low percent cover of aquatic macrophytes may be associated with reduced productivity, possibly reflecting low nutrient levels or salinization (Rooney and Bayley 2012). Furthermore, at the scale of the study area, wetland communities varied significantly among each area of interest. Successional trajectories appear to be mediated by topographic variation (e.g., in elevation and $\%$ slope) in combination with the reclamation substrates that were placed prior to seeding/planting (Fig. 6). For example, presence of Rego Gleysols, Rego Humic Gleysols, and placed overburden was correlated with higher cover of obligate wetland species such as common cattail and great bulrush, while peat-mineral caps tended to be associated with more transitional (facultative) wetland plant associations. More extensive data are required on the reclamation substrates used at various wetland sites to understand how closely wetland plant composition is correlated with substrate type. Nevertheless, our preliminary results suggest that wetland development is sensitive to the specific substrates used at different locations, and that prior knowledge of substrate types will be important when making predictions about wetland development trajectories.

Most of the reclaimed landforms assessed for this study are between 6- and 19-years post-reclamation 
and can be characterized as early seral. The possible role that opportunistically forming wetlands can play in mitigating impacts to wetland habitats stemming from bitumen extraction in the Athabasca Oil Sands Region has only recently been considered (this study and Little-Devito et al. 2019). As noted by LittleDevito et al. (2019), the presence of opportunistic wetlands could help fulfil some of the reclamation requirements associated with wetland habitat loss mitigation. Their relative ubiquity at Suncor's Base Plant, combined with their seasonal persistence and year-over-year continuity, suggests that opportunistic wetlands may have a greater influence on the closure landscape than previously recognized. The conditions that seem to promote spontaneous wetland development, such as topographical contouring, heterogeneity of soil cover placements (in terms of depth and composition), and elevated water-holding capacity, may be an inevitable if unintended outcome of current land reclamation practices at Suncor's Base Plant mine and Syncrude's Mildred Lake Lease and, by extension, at other AOSR mines as well.

As more areas are reclaimed to upland forest types planted on a peat-mineral or a forest floor mineral mix substrate, more opportunistic wetlands are prone to develop in situ. The spontaneous appearance of wetlands on reclaimed areas presents an opportunity to consider the intentional facilitation of such features (e.g., via surface contouring or targeted plant seeding) as a potential complementary approach to compensating for habitat impacts to the pre-mine boreal landscape. Certainly, the presence of numerous small wetlands (at least 619 at Suncor Base Plant) has the potential to increase the ecological heterogeneity of upland reclaimed landforms, increase wildlife habitat suitability, and provide hydrologic functions (LittleDevito et al. 2019; Hawkes and Gerwing 2019). For example, Hawkes and Gerwing (2019) found that wildlife (i.e., small mammal, large mammal, songbird, amphibian) communities on reclaimed uplands across the AOSR exhibited 31-62\% (average 52\%) similarity within 33 years of reclamation. It is reasonable to surmise that the time required for wildlife utilization of opportunistic wetlands to begin to converge with that of regional natural wetlands could be even less, given that shallow open water, marshes, and shrubby swamps can form quickly (within a few years) and probably reach functional maturity within a much shorter timeframe than mixedwood forest. One environmentally sensitive, wetland-dependent taxonomic guild that has already succeeded in occupying opportunistic wetland habitat at Suncor is amphibians [including Wood Frog (Lithobates sylvaticus), Boreal Chorus Frog (Pseudacris maculata), and Canadian Toad (Anaxyrus hemiophrys); unpubl. Data]. Colonization by amphibians has occurred despite the numerous and obvious barriers to dispersal (e.g., open mines, roads, tailings) that exist between many reclamation sites and neighbouring occupied natural sites, reinforcing the idea that opportunistic wetlands could have a role in assisting oil sands operators to meet their regulatory requirements and obligations around wildlife habitat mitigation.

Most wetlands sampled (93\%) were less than 1 ha in size (Fig. 4). The maximum water table of these wetlands is just below or above the ground surface, and while their presence could pose a threat to the geotechnical stability of constructed upland landforms, this appears unlikely due to their shallow profiles and high evaporative potential (CEMA 2014; Little-Devito et al. 2019). A recent internal study by Suncor corroborates this, at least for two reclaimed landforms on their Base Plant mine (areas 3 and 4 in Fig. 1). Both upland areas are mining waste dumps without tailings. Wetlands were evaluated relative to their location (e.g., position relative to the crest of a slope) and water depth to determine if their presence represented a threat to the structural stability of the landforms. The internal report did not identify any significant concerns stemming from the occurrence or distribution or opportunistic wetlands for the areas assessed but future monitoring was recommended (Suncor, unpubl. data). However, given that many reclaimed uplands are built with mine tailings necessitating that they be capped, the potential short- and long-term risks to landform integrity need further investigation. Likewise, the longevity of opportunistic wetlands relative to forest succession and changing climatic regimes is presently unknown (Little-Devito et al. 2019). As adjacent planted or naturally establishing upland plant communities begin to mature and increase their draw upon the water table through evapotranspiration, many smaller marshes and shallow open water wetlands will likely fill in and succeed first to shrubby swamp before transitioning to upland forest or drier, graminoid-dominated shrubland over time. During field verifications we observed various signs of successional transition already underway, for 
example, in the form of willows (Salix spp.) establishing over former cattail stands and encroachment of mixed woody shrubs into wet meadow zones of marshes (Fig. 2c). Likewise, large areas of delineated swamp habitat appeared to be situated well above the water table and supported both planted spruce (Picea glauca) as well as stands of regenerating aspen and poplar (Populus tremuloides, P. balsamifera), all common components of adjacent mixedwood stands.

Given that most of the reclamation planned for the AOSR is scheduled to occur post-2035 (Pickard et al. 2013), greater understanding of the interplay between opportunistic wetland development, upland reclaimed landforms, wildlife use, and wetland persistence on those landscapes is required for purposes of reclamation tracking as it pertains to mine closure plans and habitat reclamation.

\section{Conclusions}

Remote imaging can be an effective tool for identifying instances of opportunistic wetland formation on reclaimed upland landforms in the Athabasca Oil Sands Region, but additional field truthing will probably be needed to accurately delimit the extents of individual wetland complexes. This applies to both intentionally reclaimed (constructed) and non-intentional (opportunistic) wetlands. Even when ground surveys are used, deriving precise wetland coverage estimates for a single large reclamation area (more so for the entire mine area) can be challenging due to both the complexity of the terrain at the micro-scale and the large aerial extents occupied by certain wetland classes such as shrubby swamp. It is thus hoped that further explorations with remote sensing approaches will yield improvements to desktop-based mapping. For example, the inclusion of other topographic indexes aside from TWI (topographic wetness index) such as the downslope distance gradient could increase the accuracy of wetland detection and delineation.

Wetland and forest ecosystems are affected by bitumen extraction in the AOSR. Oil Sands operators have an obligation to reclaim and this requires the creation of functional habitats with equivalent land capability. Most reclamation that has occurred to date has focused on reclaiming constructed landforms to an upland forest type consistent with the surrounding and naturally occurring boreal forest (Pinno and Hawkes 2015; Hawkes and Gerwing 2019). Although unintended, the interspersion of opportunistic wetlands with upland reclaimed landforms more closely reflects the pre-disturbance upland landscape, which was characterized by a matrix of peatlands, forested ecosystems, and mineral wetlands. The inclusion of opportunistic wetland development in reclamation tracking and closure planning merits consideration as does the opportunity to manipulate current reclamation practices to promote the establishment and persistence of wetlands on reclaimed landforms (Little-Devito et al. 2019). When combined with purposeful (intentional) wetland creation, the formation of opportunistic wetlands on reclaimed upland landforms can contribute to the development of forest-peatlandmineral wetland mosaics that were once abundant in the mineable portion of the AOSR, thereby assisting with the process of mitigating the impacts associated with this particular natural resource extraction.

Acknowledgments The authors would like to acknowledge logistical support provided by Suncor Field Services. Bryce McKinnon (LGL Limited) and Jonna Jacobs (Soil Groundwork Consulting Inc.) assisted with data collection. Travis Gerwing assisted with data analysis (PERMANOVA, nMDS plots). We thank three anonymous reviewers for their contributions to our manuscript.

Open Access This article is licensed under a Creative Commons Attribution 4.0 International License, which permits use, sharing, adaptation, distribution and reproduction in any medium or format, as long as you give appropriate credit to the original author(s) and the source, provide a link to the Creative Commons licence, and indicate if changes were made. The images or other third party material in this article are included in the article's Creative Commons licence, unless indicated otherwise in a credit line to the material. If material is not included in the article's Creative Commons licence and your intended use is not permitted by statutory regulation or exceeds the permitted use, you will need to obtain permission directly from the copyright holder. To view a copy of this licence, visit http://creativecommons.org/licenses/by/4.0/.

Funding This work was funded by Suncor Energy Inc. through contracts to LGL Limited environmental research associates.

\section{References}

Alberta Environment (2000) Guidelines for the approval and design of natural and constructed treatment wetlands or 
water quality improvement. Available from https://open. alberta.ca/dataset/077851045x

Alberta Environment and Parks (AEP) (2014) Guide for assessing permanence of wetland basins. Land Policy Branch, Alberta Environment and Parks, Edmonton, p 28

Alberta Environment and Sustainable Resource Development (AESRD) (2015) Alberta Wetland Classification System. Water Policy Branch, Policy and Planning Division, Edmonton

Amani M, Salehi B, Mahdavi S, Brisco B (2018) Spectral analysis of wetlands using multi-source optical satellite imagery. ISPRS J Photogramm Remote Sens 144:119-136

Anderson M, Gorley RN, Clarke RK (2008) Permanova+ for primer: guide to software and statistical methods. PRIMER-E Ltd, Plymouth

Borkenhagen A, Cooper D (2015) Creating fen initiation conditions: a new approach for peatland reclamation in the oil sands region of Alberta. J Appl Ecol 53:550-558

Borkenhagen A, Cooper D (2019) Establishing vegetation on a constructed fen in a post-mined landscape in Alberta's oil sands region: a four-year evaluation after species introduction. Ecol Eng 130:11-22

Calhoun AJK, Mushet DM, Bell KP, Boix D, Fitzsimons AJ, Isselin-Nondedeu F (2017) Temporary wetlands: challenges and solutions to conserving a 'disappearing' ecosystem. Biol Conserv 211:3-11

Clarke KR (1993) Non-parametric multivariate analyses of changes in community structure. Aust $\mathrm{J}$ Ecol 18(1):117-143

Clarke KR, Gorley RN (2015) PRIMER v7: user manual/tutorial, 3rd edn. Primer-E Ltd., Plymouth

Cumulative Environmental Management Association (CEMA) (2014) Guidelines for wetlands establishment on reclaimed oil sands leases. In: West Hawk Assoc for the Reclamation Working Group and the Aquatic Sub-Group and Wildlife Task Group of the Cumulative Environmental Management Association (ed) 3rd edn. https://cemaonline.ca/ index.php/administration/cat_view/2-communications/18rwg-recommendations

Daly C, Atkinson J, Birrkam T, Chapman D, Ciborowski J, O'Kane M, McKenna G, Price JS, Rochefort L, and Russell B (2010) Novel wetland reclamation design: the Suncor Pilot Fen and Wapisiw Wetland. In: Proceedings from the 37th Aquatic Toxicity Workshop, October 3-6, Toronto

Daly C, Price J, Rezanezhad F, Pouliot R, Rochefort L, Graf M (2012) Initiatives in oil sand reclamation: considerations for buildings fen peatland in a post-mined oil sands landscape. In: Vitt DH, Bhatti J (eds) Restoration and reclamation of boreal ecosystems-attaining sustainable development. Cambridge University Press, Cambridge, pp 179-201

Daly C, Tedder W, Marlowe P (2009) Recreating wetlands ecosystems in and oil sands disturbed landscape: Suncor consolidated-tailings demonstration wetlands. Can Land Reclam Assoc Can Reclam Mag 2009(2):52-56

Daly CA (2011) History of wetland reclamation in the Alberta oil sands. In: Proceedings of the Sixth International Conference on Mine Closure (Mine Closure 2011). 19-21 September. Lake Louise, pp 535-544

Gingras-Hill T, Nwaishi FC, Macrae ML, Price JS, Petrone RM (2018) Ecohydrological functioning of an upland undergoing reclamation on post-mining landscape of the Athabasca oil sands region, Canada. Ecohydrology 11(3):e1941. https://doi.org/10.1002/eco.1941

Government of Alberta (2015) Alberta wetland identification and delineation directive. Water Policy Branch, Alberta Environment and Parks, Edmonton

Government of Alberta (2017b) Environmental Protection and Enhancement Act: conservation and reclamation regulation. Alberta Regulation 134-146

Government of Alberta (2017a) Facts and statistics. Available from https://open.alberta.ca/dataset/b6f2d99e-30f8-4194b7eb-76039e9be4d2/resource/063e27cc-b6d1-4dae-835644e27304ef78/download/fsoilsands.pdf (accessed 17 June 2020)

Grabs T, Seibert J, Bishop T, Laudon H (2009) Modeling spatial patterns of saturated areas: a comparison of the topographic wetness index and a dynamic distributed model. J Hydrol 373:15-23

Hawkes VC, Gerwing TG (2019) Wildlife usage indicates increased similarity between reclaimed upland habitat and mature boreal forest in the Athabasca Oil Sands Region of Alberta, Canada. PLoS ONE 14:e0217556

Hemstock SS, Quideau SA, Chanasyk DS (2010) Nitrogen availability from peat amendments used in boreal oil sands reclamation. Can J Soil Sci 90:165-175

Hjerdt KN, McDonnell, JJ, Seibert, J, Rodhe, A (2004) A new topographic index to quantify downslope controls on local drainage. Water Resour Res 40:W05602. https://doi.org/ 10.1029/2004WR003130

Ketcheson S, Price JS, Sutton O, Sutherland G, Kessel E, Petrone RM (2017) The hydrological functioning of a constructed fen wetland watershed. Sci Total Environ 603-604:593-605

Ketcheson SJ, Price JS, Carey SK, Petrone RM, Mendoza CA, Devito KJ (2016) Constructing fen peatlands in post-mining oil sands landscapes: challenges and opportunities from a hydrological perspective. Earth-Sci Rev 161:130-139

Kincaid TM, Olsen AR (2016) spsurvey: spatial survey design and analysis. $\mathrm{R}$ package version 3.3

Little-Devito M, Mendoza AC, Chasmer L, Kettridge N, Devito KJ (2019) Opportunistic wetland formation on reconstructed landforms in a sub-humid climate: influence of site and landscape-scale factors. Wetl Ecol Manage 27:587-608

MacKenzie MD, Quideau SA (2010) Microbial community structure and nutrient availability in oil sands reclaimed boreal soils. Appl Soil Ecol 44:32-41

Miller M, Novoa J, Hawkes VC, McKinnon B, Gerwing T (2017) Wetland inventory of permanently reclaimed sites at Suncor Oil Sands Base Plant. Unpublished report by LGL Limited environmental research associates, Sidney, $\mathrm{BC}$ for Suncor Energy, Calgary, $35 \mathrm{pp}+\mathrm{App}$

Mollard FPO, Roy M, Foote AL (2015) Performance of wetland forbs transplanted into marshes amended with oil sands processes water. Environ Monit Asess 187(3):125. https:// doi.org/10.1007/s10661-015-4365-1

Natural Regions Committee (NRC) (2006) Natural Regions and sub-regions of Alberta. Compiled by DJ Downing and WW Pettapiece; Government of Alberta. Pub. No. T/852. https://www.albertaparks.ca/media/2942026/ nrsrcomplete_may_06.pdf (accessed 14 August 2019) 
Novoa J, Hawkes VC (2016) Wetland inventory of permanently reclaimed sites at Suncor oil sands base plant. Unpublished report by LGL Limited environmental research associates, Sidney, BC for Suncor Energy, Calgary, $28 \mathrm{pp}$

Nwaishi F, Petrone RM, Price JS, Andersen R (2015a) Towards developing a functional-based approach for constructed peatlands evaluation in the Alberta oil sands region, Canada. Wetlands 35:211-225

Nwaishi F, Petrone, RM, Price, JS, Ketcheson, SJ, Slawson R, Andersen R (2015b) Impacts of donor-peat management practices on the functional characteristics of a constructed fen. Ecol. Eng. 81:471-480. https://doi.org/10.1016/j. ecoleng.2015.04.038

Pickard D, Hall A, Murray C, Frid L, Schwarz C, Ochoski N (2013) Long-term plot network: effectiveness monitoring program. Prepared for the Plot Network Task Group, Terrestrial Subgroup, Reclamation Working Group, Cumulative Environmental Management Association (CEMA), Fort McMurray, 108 pp.

Pinno BD (2015) Hawkes VC (2015) Temporal trends of ecosystem development on different site types in reclaimed boreal forests. Forests 6:2109-2124. https://doi.org/10. 3390/f6062109

Pollard J, McKenna GT, Fair J, Daly C, Wytrykush C, Clark J (2012) Design aspects of two fen wetlands constructed for reclamation research in the Athabasca oil sands. In: Fourie AB, Tibbett M (eds) Mine closure 2012. Australian Centre for Geomechanics, Brisbane, pp 815-829

Price JS, mclaren RG, Rudolph DL (2010) Landscape restoration after oil sands mining: conceptual design and hydrological modelling for fen reconstruction. Int J Min Reclam Env 24:109-112

Raine M, Mackenzie I, Gilchrist I (2002) CNRL Horizon Project environmental impact assessment. Vol 6 Appendix B. Terrestrial Vegetation, Wetlands and Forest Resources Baseline (Golder Associates, Calgary, AB), Report no. 012-2220

Rooney RC, Bayley SE (2012) Development and testing of an index of biotic integrity based on submersed and floating vegetation and its application to assess reclamation wetlands in Alberta's oil sands area, Canada. Environ Monit Assess 184:749-761

Rooney RC, Bayley SE, Schindler DW (2012) Oil sands mining and reclamation cause massive loss of peatland and stored carbon. PNAS 109(13):4933-4937

Scarlett SJ, Petrone RM, Price JS (2017) Controls on plot scale evapotranspiration from a constructed fen in the Athabasca Oil Sands Region, Alberta. Ecol Eng 100:199-210. https:// doi.org/10.1016/j.ecoleng.2016.12.020

Stevens DL, Olsen AR (2004) Spatially balanced sampling of natural resources. J Am Stat Assoc 99:277-624

Trites M, Bayley SE (2009) Vegetation communities in continental boreal wetlands along a salinity gradient: implications for oil sands mining reclamation. Aquat Bot 91(1):27-39

Vitt DH, Chee W-L (1989) The vegetation, surface water chemistry and peat chemistry of moderate-rich fens in central Alberta, Canada. Wetlands 9(2):227-261

Vitt DH, House M, Hartsick JA (2016) Sandhill fen, an initial trial for wetland species assembly on in-pit substrates: lessons after three years. Botany 94(11):1015-1025. https://doi.org/10.1139/cjb-2015-0262

Volik O, Elmes M, Petrone R, Kessel E, Green A, Cobbaert D, Pirce J (2020) Wetlands in the Athabasca Oil Sands Region: the nexus between wetland hydrological function and resource extraction. Environ Rev. https://doi.org/10. 1139/er-2019-0040

Wytrykush C, Vitt DH, McKenna G, Vassov R (2012) Designing landscapes to support peatland development on soft tailings deposits. In: Vitt DH, Bhatti J (eds) Restoration and reclamation of boreal ecosystems. Cambridge University Press, Cambridge, pp 161-217

Publisher's Note Springer Nature remains neutral with regard to jurisdictional claims in published maps and institutional affiliations. 